\title{
Grim-19 expressed by recombinant adenovirus for esophageal neoplasm targeted therapy
}

\author{
JIANXIANG SONG ${ }^{1,2^{*}}$, WODA SHI ${ }^{1,2^{*}}$, WENCAI WANG $^{2}$, YAJUN ZHANG ${ }^{2}$ and SHIYING ZHENG ${ }^{1}$ \\ ${ }^{1}$ Department of Cardiothoracic Surgery, The First Affiliated Hospital of Soochow University, Suzhou, Jiangsu 215006; \\ ${ }^{2}$ Department of Cardiothoracic Surgery, The Third People's Hospital, Yancheng, Jiangsu 224001, P.R. China
}

Received March 24, 2016; Accepted September 6, 2017

DOI: $10.3892 / \mathrm{mmr} .2018 .8638$

\begin{abstract}
Esophageal squamous cell carcinoma (ESCC) and esophageal adenocarcinoma (EA) are the two most common types of esophageal cancer, which is the sixth highest cause of cancer-associated mortality and the eighth most common cancer worldwide. Gene associated with retinoid-interferon (IFN)-induced mortality-19 (Grim-19) is reported to be a cell death activator that may be used to define mechanisms involved in IFN- $\beta$ - and retinoic acid-induced cell death and apoptosis in a number of tumor cell lines. The present study constructed a recombinant adenovirus expressing Grim-19 (rAd-Grim-19) and investigated its therapeutic outcomes in ESCC cells and tumor-bearing mice. Grim-19 expression was detected in EC-109 (ESCC) cells by reverse transcription-quantitative polymerase chain reaction and western blot analysis. Tumor cell death and apoptosis induced by rAd-Grim-19 in EC-109 cells were analyzed by flow cytometry. The inhibitory effects of rAd-Grim-19 on EC-109 growth were determined by MTT assays. Furthermore, the therapeutic effects of rAd-Grim-19 were investigated in EC-109-bearing mice. The results demonstrated that Grim-19 mRNA and protein expression was downregulated in EC-109 esophageal carcinoma cells compared with Het-1A normal esophageal epithelial cells. In addition, EC-109 cells exhibited a significant reduction in tumor cell growth in the rAd-Grim-19 group compared with the control groups. Furthermore, rAd-Grim-19 increased EC-109 cell apoptosis compared with the control group. These results indicated that $\mathrm{rAd-Grim-19}$ may regulate tumor cell growth and apoptosis. Additionally, the results demonstrated that rAd-Grim-19 led to beneficial outcomes and prolonged the
\end{abstract}

Correspondence to: Professor Shiying Zheng, Department of Cardiothoracic Surgery, The First Affiliated Hospital of Soochow University, 48 Suhang Road, Suzhou, Jiangsu 215006, P.R. China E-mail: zhenghaiying951@163.com

*Contributed equally

Key words: gene associated with retinoid-interferon-induced mortality-19, recombinant adenovirus, esophageal squamous cell carcinoma, apoptosis survival of esophageal tumor-bearing mice. In conclusion, the present study demonstrated that rAd-Grim-19 may have potential as an antitumor agent for esophageal neoplasms and may therefore be beneficial for patients with esophageal neoplasms.

\section{Introduction}

Esophageal neoplasm is one of most common human cancers in Africa, South America, China, Europe and North America, and includes esophageal squamous cell carcinoma (ESCC) and esophageal adenocarcinoma (EA), small cell undifferentiated carcinoma and sarcoma divided by histological types (1). Previous reports have indicated that the globalincidence of esophageal neoplasm has increased $\sim 500 \%$ over the past 30 years (2-4). Statistics indicate that ESCC and EA account for 95 and $5 \%$ of esophageal cancer diagnoses, respectively $(5,6)$. As the number of patients diagnosed with esophageal cancer is increasing, there is a focus on the development of novel strategies for early esophageal neoplasm diagnosis and treatments using novel and efficient anticancer treatments, including surgical treatment, radiotherapy, chemical therapy, biological therapy and comprehensive therapy for patients (7-9).

The expression of oncogenic and oncolytic proteinsin human tumors has previously been investigated to analyze gene expression patterns during cellular transcription and translation, in addition to tumor cell growth, migration and invasion (10-12). Gene associated with retinoid-interferon (IFN)-induced mortality-19 (Grim-19) is reported to be a cell death activator that is used to define mechanisms involved in IFN- $\beta$ - and retinoic acid-induced cell death and apoptosis in various tumor cell lines (13). Oncolytic proteins have been demonstrated to inhibited tumor cell growth by activating specific sets of genes and initiating the apoptotic program of cells (14). In a previous study, Grim-19 upregulation exhibited antitumor effects via induction of IFN- $\beta$ and retinoic acid in human tumor cells (15). Li et al (15) reported that Grim-19 upregulation inhibited signal transducer and activator of transcription 3 (STAT3) transcriptional activity by constitutive inactivation of the signal transducer, and this regulatory pathway contributed to the inhibition of progression and metastasis in several different tumor types. In addition, Grim-19 bound to the transcription factor STAT3 and led to the ablation of pro-oncogenes Fas cell surface death receptor and Jun proto-oncogene, and inhibition of the pro-oncogenic 
effects of v-Src independently of STAT3 (16). Furthermore, reduced Grim-19 expression was reported to beassociated with high-risk human papilloma virus infection in cervical squamous intraepithelial neoplasia and cancer (17).

Adenovirus vectors are the most widely used vectors and adenovirus-mediated delivery of antitumor genes or polypeptides into tumor cells has been described extensively $(18,19)$. In addition, gene transfer strategies have presented increased clinical potential for clinicians, which may be applied asimmunotherapy for patients with cancer using oncolytic proteins delivered by recombinant adenovirus (rAd) to exert various effects, including inhibition of oncogenes and restoration of tumor suppressor genes, immunotherapy, anti-angiogenesis and virotherapy (20).

The present study investigated the efficacy of rAd expressing Grim-19 (rAd-Grim-19) on esophageal tumor growth and investigated the potential for rAd-Grim-19 as a therapeutic intervention for patients with esophageal cancer. The results of the current study indicated that esophageal tumor growth was suppressed by rAd-Grim-19 and survival was prolonged during a 120-day observation period, indicating that rAd-Grim-19 may be an efficient antitumor agent for patients with esophageal neoplasm.

\section{Materials and methods}

Ethics statement. The investigation was conducted according to the Guide for the Care and Use of Laboratory Animals (21). All experimental protocols and surgery on animals were performed in accordance with the First Affiliated Hospital of Soochow University on theEthics of Animal Experiments Defense Research (Suzhou, China). All surgical operations and euthanasia were performed in a manner that minimized suffering.

Patients. A total of 5 patients with esophageal tumor ( 2 female and 3 male; mean age, 54.2 years old) were admitted to the First Affiliated Hospital of Soochow University (Suzhou, China) between May 2013 and January 2014. Both human and animal experiments were approved by Ethics Committee of the First Affiliated Hospital of Soochow University.

Construction of recombinant adenovirus by genetic engineering. Adeno-X expression system (cat. no. 632269; Takara Biotechnology Co., Ltd., Dalian, China) was used for the construction of recombinant adenovirus. Human Grim-19 (the First Affiliated Hospital of Soochow University, Suzhou, China) linked with cell-penetrating peptide was extracted as previously described (22) and cloned into the pAd-X expression system plasmid. The recombinant adenoviral plasmid expressing Grim-19 was selected and confirmed by polymerase chain reaction (PCR) and sequencing (Invitrogen; Thermo Fisher Scientific, Inc., Waltham, MA, USA), and is termed rAd-Grim-19. The recombinant adenoviruses (5 MOI) were generated by transfecting into 293 cells $\left(1 \times 10^{6}\right)$ for $144 \mathrm{~h}$ at $37^{\circ} \mathrm{C}$ and followed 10th generation propagation to purify viruses. rAd-Grim-19 was purified as described in a previous report (23). The titers of rAd-Grim-19 and rAd were determined by $\mathrm{TCID}_{50}$ as plaque-forming units $(\mathrm{pfu}) / \mathrm{ml}$. The EC-109 cells $\left(1 \times 10^{4}\right)$ divided into three treatment groups: i) The control group (PBS); ii) the rAd group $\left(0.25 \mathrm{mg} / \mathrm{ml}\right.$ at $37^{\circ} \mathrm{C}$ for $\left.24 \mathrm{~h}\right)$; and iii) the rAd-Grim-19 group $\left(0.25 \mathrm{mg} / \mathrm{ml}\right.$ at $37^{\circ} \mathrm{C}$ for $\left.24 \mathrm{~h}\right)$.

Cell culture. EC-109 and Het-1A cells were purchased from American Type Culture Collection (Manassas, VA, USA). All cells were cultured in EMEM supplemented with $10 \%$ fetal bovine serum (FBS; Gibco; Thermo Fisher Scientific, Inc.) at $37^{\circ} \mathrm{C}, 5 \% \mathrm{CO}_{2}$ and reasonable humidity.

MTT assay. EC-109 cells $\left(1 \times 10^{3}\right)$ were cultured and then inoculated with rAd-Grim-19 [0.5 multiplicity of infection (MOI)] or rAd-EGFP 0.5 (MOI) or PBS in 96-well plates for $48 \mathrm{~h}$ at $37^{\circ} \mathrm{C}$ in triplicate for each condition. Following culture, $20 \mu \mathrm{l}$ MTT $(5 \mathrm{mg} / \mathrm{ml})$ in PBS solution was added to each well, the plate was further incubated for $4 \mathrm{~h}$ at $37^{\circ} \mathrm{C}$. The medium was entirely removed and $100 \mu 1$ dimethyl sulfoxide was added to the wells to solubilize the crystals. The optical density (OD) was measured using an ELISA microplate reader (Bio-Rad Laboratories, Inc., Hercules, CA, USA) reader at a wave length of $450 \mathrm{~nm}$.

Reverse transcription-quantitative PCR (RT-qPCR). Total RNA was obtained from EC-109 cells and Het-1A normal esophageal epithelial cells by using an RNA easy Mini kit (Qiagen Sciences, Inc., Gaithersburg, MD). The expression of Grim-19 in EC-109 and Het-1A cells was measured using a RT-qPCR kit (Qiagen Sciences, Inc.) with $\beta$-actin expression as an endogenous control, according to the manufacturer's protocol. All the primers (Grim-19 forward, 5'-TCGGGG ACTGTCGGGGTAC-3' reverse, 5'-AGGGTCCTCCGG TCCTTCT-3'; $\beta$-actin forward, 5'-CGGAGTCAACGGATT TGGTC-3', reverse, 5'-AGCCTTCTCCATGGTCGTGA-3') were synthesized by Invitrogen (Thermo Fisher Scientific, Inc., Waltham, MA, USA). cDNA (10 ng) was used for qPCR with the SYBR-Green Master Mix system (Bio-Rad Laboratories, Inc.; $50 \mathrm{ng}$ of genomic DNA, $200 \mu \mathrm{M}$ dNTP, 2.5 units of Taq DNA polymerase, and $200 \mu \mathrm{M}$ primers) performed followed by initial denaturation at $94^{\circ} \mathrm{C}$ for $2 \mathrm{~min}$, followed by 45 cycles of $94^{\circ} \mathrm{C}$ for $30 \mathrm{sec}$, annealing temperature reduced to $58^{\circ} \mathrm{C}$ for $30 \mathrm{sec}$ and $72^{\circ} \mathrm{C}$ for $10 \mathrm{~min}$. Relative Grim-19 expression levels were calculated by the $2^{-\Delta \Delta C q}$ method (24). The results are presented relative to $\beta$-actin.

Animal study. A total of 60 male BALB/c (SPF) nude mice (6-week-old; 26-35 g body weight) were purchased from SLAC Laboratory Animal Co., Ltd. (Shanghai, China). All animals were fed under pathogen-free conditions. All mice were housed under controlled temperature $\left(23 \pm 1^{\circ} \mathrm{C}, 50-60 \%\right.$ humidity, $0.02-0.03 \% \mathrm{CO}_{2}$ ) in a $12 \mathrm{~h}$ light/dark cycle with free access to food and water. A total volume of $200 \mu \mathrm{l}$ EC-109 cells $\left(1 \times 10^{6}\right)$ were injected into the left flank of male BALB/c nude mice. EC-109-bearing mice were treated with PBS, rAd and rAd-Grim-19 when tumor diameters reached 5-8 mm on day 6 after tumor inoculation. Tumor-bearing mice were randomly divided into 3 groups $(n=20)$ and intratumorally treated with $2 \times 10^{8}$ pfurAd or rAd-Grim-19, and PBS was used as a control. Treatments were performed 10 times at 2 day intervals. Tumor diameters were recorded every 2 days and tumor volume was calculated by using the following formula: 
$0.52 \times$ smallest diameter ${ }^{2}$ x largest diameter. Furthermore, a 120-day observation was employed to evaluate the long-term efficacy of rAd-Grim-19. The mice were euthanized when the tumor reached $10 \mathrm{~mm}$. All experimental mice were housed for a total of 120 days.

Splenocyte collection and cytotoxic T lymphocyte (CTL) responses. Splenocytes were isolated from the spleens of the therapeuticmice with esophageal neoplasm on day 30 as previously described (25). The splenocytes $\left(1 \times 10^{6}\right)$ were incubated with the mitomycin $(10 \mu \mathrm{g} / \mathrm{ml}$; Sigma-Aldrich; Merck KGaA, Darmstadt, Germany)-inactivated EC-109 cells $\left(1 \times 10^{6}\right)$ for $6 \mathrm{~h}$ at $37^{\circ} \mathrm{C}$ after washing with PBS. Supernatants were obtained using centrifugation $(2,000 \mathrm{x} \mathrm{g})$ for $10 \mathrm{~min}$ at $37^{\circ} \mathrm{C}$. Release of IFN- $\gamma$ was determined by ELISA (cat. no ab46025; Abcam, Cambridge, UK) in the supernatants after culture for $72 \mathrm{~h}$. In addition, $\mathrm{T}$ cells $\left(1 \times 10^{6}\right)$ were purified from the splenocytesas previously described (26) and cultured with EC-109 cells for $4 \mathrm{~h}$ at the effector: Target ratios of 6:1, 12:1 and 24:1 (27). Specific CTL activity of T cells for tumor cells was performed by MTT cytotoxicity assays (28).

Flow cytometry analysis. EC-109 cells were obtained from the American Type Culture Collection (Manassas, VA, USA) and cultured in minimum essential medium supplemented with $10 \%$ fetal calf serum. EC-109 cells $\left(1 \times 10^{6}\right)$ were treated with PBS, rAd and rAd-Grim-19 for $72 \mathrm{~h}$ at $37^{\circ} \mathrm{C}$. Subsequently, apoptosis in suspended cells was analyzed by flow cytometry using Annexin V-FITC and PI (Annexin V-FITC kit; BD Biosciences, Franklin Lakes, NJ, USA). In addition, on day 30 cells $\left(1 \times 10^{6}\right)$ from tumors in mice treated with PBS, rAd and rAd-Grim-19 were prepared for PE-CD4 ${ }^{+}$and PI-CD8 ${ }^{+}$ analysis by fluorescence-activated cell sorting. Tumors were removed from euthanized animals and tumor cells were isolated by passing through $100 \mu$ m nylon mesh filters and then cells washed with PBS and resuspended. Tumor cells were labeled by CD3 and CD45, followed by PE-CD4 ${ }^{+}(1: 2,000$, cat no. 88-8999-40; Thermo Fisher Scientific, Inc.) and PI-CD8 ${ }^{+}$ (1:2,000, cat no. 8804-6825-74; Thermo Fisher Scientific, Inc.) for $4 \mathrm{~h}$ at $4^{\circ} \mathrm{C}$, staining to determine the frequency of CD4 and CD8 cell subsets in the total infiltrated immune cells. Cells were washed with PBST three times and the stained cells were analyzed by using a FACScan flow cytometer (BD Biosciences) and analyzed using BD FACSDiva ${ }^{\mathrm{TM}}$ software (version 1.2; BD Biosciences).

Western blot analysis and histological immunostaining. EC-109 and Het-1A cells were lysed and used to analyzed Grim-19 protein expression, according to a previous study (29). For immunostaining, EC-109 cells $\left(1 \times 10^{6}\right)$ pre-treated with PBS, rAd or rAd-Grim-19 for $24 \mathrm{~h}$, or tumors from esophageal carcinoma xenograph mice in PBS, rAd and rAd-Grim-19 groups on day 30 were fixed using $10 \%$ for maldehyde for $15 \mathrm{~min}$ at room temperature and embedded in paraffin. Protein concentration was measured by a Bicinchoninic acid protein assay kit (Thermo Scientific, Pittsburgh PA, USA). Protein samples $(20 \mu \mathrm{g} /$ lane) wereseparated by $15 \%$ SDS-PAGE and then transferred to polyvinylidene fluoride membrane. After $1 \mathrm{~h}$ blocking at $37^{\circ} \mathrm{C}$ temperature using $10 \%$ blocking reagent (Roche Applied Science, Penzberg, Germany), membrane was incubated with primary antibodies: Grim-19 (1:1,000; cat. no. ab134325; Abcam) and $\beta$-actin (1:1,000, cat. no. ab8226; Abcam) for $12 \mathrm{~h}$ at $4^{\circ} \mathrm{C}$. Following the incubation, membrane was washed three times in TBST and incubated with horseradish peroxidase-conjugated goat anti-rabbit IgG mAb (1:1,000; cat. no. PV-6001; OriGene Technologies, Inc., Beijing, China) for $1 \mathrm{~h}$ at $37^{\circ} \mathrm{C}$. After three-time washing in TBST, membrane was developed using a chemiluminescence assay system (Roche Applied Science) and exposed to Kodak exposure films. In addition, tumor samples were cut in to tumor sections $(4 \mu \mathrm{m})$ and antigen retrieval was also performed. EC-109 cells and tumor sections were incubated with TUNEL reaction mixture (Sigma-Aldrich; Merck KGaA) at $37^{\circ} \mathrm{C}$ for $2 \mathrm{~h}$. Cells were three-time washing in TBST and stained with DAPI (Sigma-Aldrich; Merck KGaA) at $37^{\circ} \mathrm{C}$ for $2 \mathrm{~h}$. TUNEL assays were conducted using a TUNEL fluorescence FITC kit (Roche, Indianapolis, IN, USA) according to the manufacturer's instructions. All sections were stained with hematoxylin and eosin $(\mathrm{H} \& \mathrm{E})$ for $2 \mathrm{~h}$ at $37^{\circ} \mathrm{C}$. Images were captured on MicroChemi 4.2 (Eastwin, Shenzen, China).

Immunohistochemistry. Esophageal tumors from patients were fixed with $10 \%$ for maldehyde, then embedded in paraffin and cut into tumor sections for $2 \mathrm{~h}$ at $37^{\circ} \mathrm{C}$. Antigen retrieval was performed on the tumor sections using eBioscience $^{\mathrm{TM}}$ IHC Antigen Retrieval Solution (cat. no 00-4955-58; Invitrogen), and the sections were subsequently incubated with rabbit anti-mouse Grim-19 (1:1,000, ab134325; Abcam). Following antibody incubation, Alexa Fluor 488-labeled secondary antibodies (1:500; Beyotime Institute of Biotechnology) for $2 \mathrm{~h}$ at $37^{\circ} \mathrm{C}$ and the specimens were visualized. A Ventana Benchmark automated Diaminobenzidine staining system (Ventana Medical Systems, Inc., Tucson, AZ, USA) was used to detect Grim-19 protein expression.

Statistical analysis. Data are presented as the mean \pm standard error of the mean of triplicate experiments. All data were analyzed using SPSS software (version 19.0; IBM Corp., Armonk, NY, USA). Unpaired data were analyzed by Student's t-test. Comparisons between multiple groups were analyzed by one-way analysis of variance followed by Bonferroni post hoc tests. The Kaplan-Meier test was used to estimate survival during the 120 -day observation period. $\mathrm{P}<0.05$ was considered to indicate a statistically significant difference.

\section{Results}

Expression of Grim-19 and its function in esophageal tumor cells. In order to analyze the function of Grim-19 in tumor cells, the present study first investigated Grim-19 expression in esophageal tumor cells. EC-109 cells were cultured and cells were harvested to isolate total RNA. Grim-19 expression was analyzed by RT-qPCR and western blot analysis. The results in Fig. 1A and B demonstrate that Grim-19 expression was downregulated in EC-109 cells at mRNA and protein levels compared with HET-1 A normal esophageal epithelial cells. In addition, the function of Grim-19 was studied in EC-109 cells. Furthermore, the results of MTT assays indicated that Grim-19 exhibited significant inhibitory effects on EC-109 cell growth (Fig. 1C), andthe results in Fig. 1D indicate that Grim-19 significantly 
A

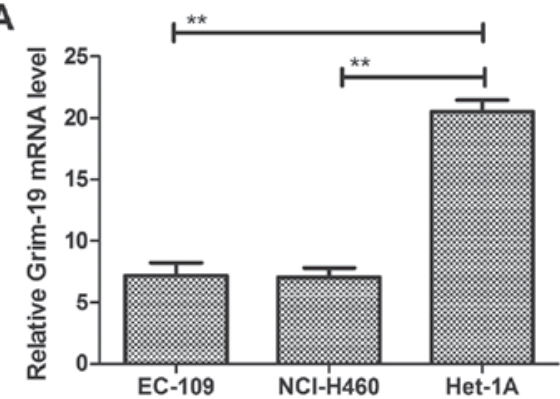

C

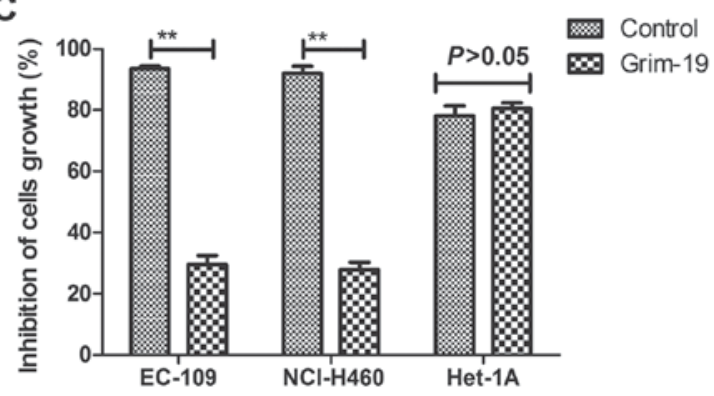

B

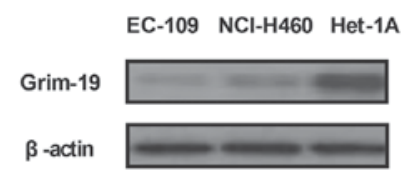

D

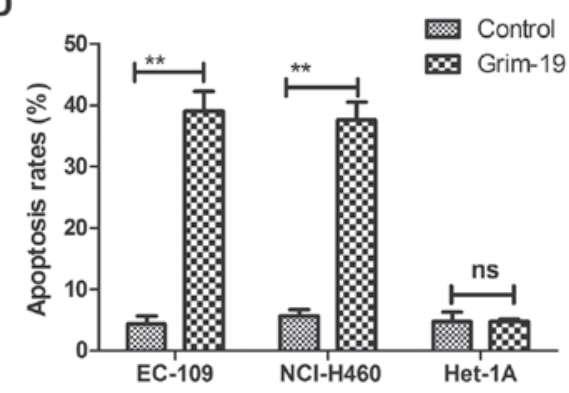

Figure 1. Grim-19 expression and its function in EC-109 cells. (A) Reverse transcription-quantitative polymerase chain reaction was performed to analyze the mRNA expression of Grim-19 in EC-109 and Het-1A cells. (B) Western blot analysis was performed to analyze the protein expression of Grim-19 in EC-109 and Het-1A cells. (C) MTT assays determined the tumorinhibition growth effects of Grim-19 on EC-109 and Het-1A cells. (D) Fluorescence-activated cell sorting was used to evaluate the apoptosis-inducing effects of Grim-19 in EC-109 and Het-1A cells. Data are presented as the mean \pm standard error of the mean. ${ }^{* *} \mathrm{P}<0.01$, as indicated. Grim-19, gene associated with retinoid-interferon-induced mortality-19.

induced apoptosis in EC-109 cells after $72 \mathrm{~h}$ treatment. These results indicated that Grim-19 expression was downregulated in EC-109 cells, and Grim-19 treatment led to growth inhibitory effects and enhanced apoptosis in EC-109 cells.

Detection and bioactivity of Grim-19 in rAd-Grim-19-infected cells in vitro. In order to investigate the effect of Grim-19 over expression, the expression of Grim-19 proteins in rAd-Grim-19-infected EC-109 cells was observed by fluorescent microscopy following incubation with anti-Grim-19 antibody. The results demonstrated that Grim-19 protein was observed in EC-109 cells infected with rAd-Grim-19, indicating that Grim-19 was efficiently expressed in tumor cells (Fig. 2A). The results in Fig. 2B indicate that Grim-19 was effectively expressed and secreted extracellularly in EC-109 cells infected with rAd-Grim-19. In addition, the kinetic curve of rAd-Grim-19 was analyzed, which demonstrated that Grim-19 gene insertion did not affect the recombinant adenovirus (Fig. 2C). Furthermore, the results demonstrated that EC-109 cell growth was significantly inhibited by rAd-Grim-19 compared with rAd and PBS groups (Fig. 2D). These results indicated that Grim-19 was efficiently upregulated by rAd-Grim-19 and rAd-Grim-19 led to tumor growth inhibitory effects on EC-109 cells.

In vivo effects of rAd-Grim-19 in esophageal tumor-bearing mice. In order to analyze the in vivo effects of rAd-Grim-19 on tumor growth inhibition, its anticancer effect was determined in an esophageal tumor-bearing mouse model. The results in Fig. 3A demonstrate that rAd-Grim-19 significantly suppressed tumor growth, while xenograft mice treated with rAd-only exhibited reduced inhibitory effects, compared with PBS treatment. The results indicate that tumors in the rAd-Grim-19-treated group decreased by a volume of $32.18 \pm 8.38 \mathrm{~mm}^{3}$ by day 25 , which is significant difference compared with the rAd and PBS groups $(\mathrm{P}<0.01)$. During the period of treatment, no side effects were observed other than swelling at the injection site. In addition, a 120-day long-term survival observation period was performed following treatment with PBS, rAd and rAd-Grim-19. The results in Fig. 3B demonstrated that rAd-Grim-19 $(n=20)$ prolonged the survival of mice compared with rAd and PBS groups. In addition, CTL responses and IFN- $\gamma$ release were determined on day 25 after treatments. The results in Fig. 3C and D indicated that mice treated with rAd-Grim-19 developed a strong CTL response for EC-109 cells and exhibited an increased release of IFN- $\gamma$ compared with rAd and PBS groups. These results demonstrate therapeutic effects of rAd-Grim-19 against EC-109 in tumor-bearing animals, as long-term survival was increased in mice treated with rAd-Grim-19.

rAd-Grim-19 increases immune cell and apoptotic body accumulation in EC-109 tumor-bearing mice. To further investigate the long-term survival of tumor-bearing mice, immune responses were analyzed and tumor challenge experiments were performed. The results in Fig. 4A demonstrate that $\mathrm{CD}^{+}$and $\mathrm{CD}^{+}$expression levels were increased in tumors from rAd-Grim-19-treated mice compared with rAd and PBS groups. Tumor challenge experiments were performed after a 120-day survival period observation. As indicated in Fig. 4B, rAd-Grim-19-treated mice demonstrated an immune memory for EC-109 tumor cells and their survival was prolonged compared with rAd-treated mice. Furthermore, apoptotic bodies were analyzed by immunohistochemistry staining in tumors from experimental mice following treatment with rAd-Grim-19, rAD and PBS. The results in Fig. 4C demonstrated that an increased number of apoptotic bodies on tumors were observed in rAd-Grim-19-treated mice compared with 
A

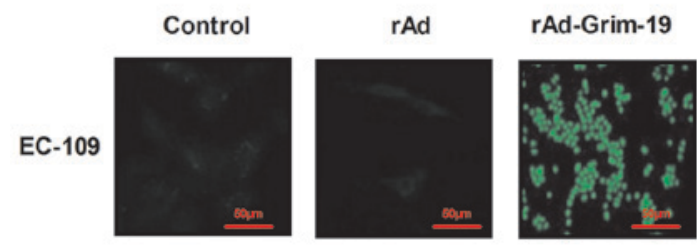

C

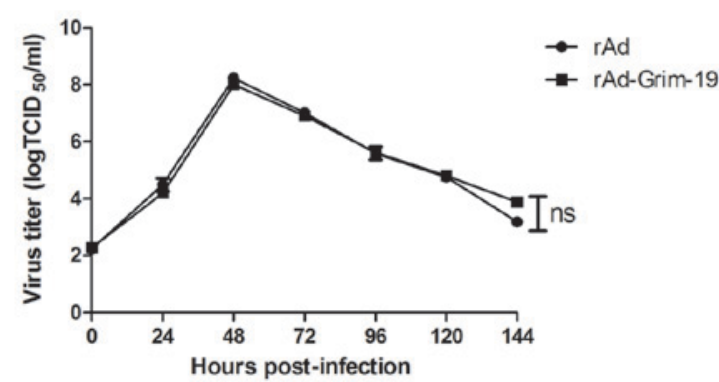

B

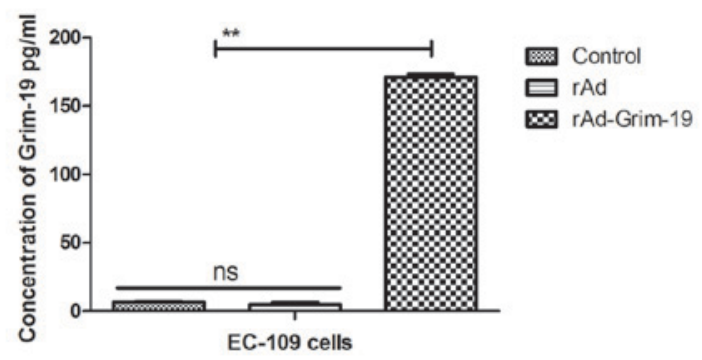

D

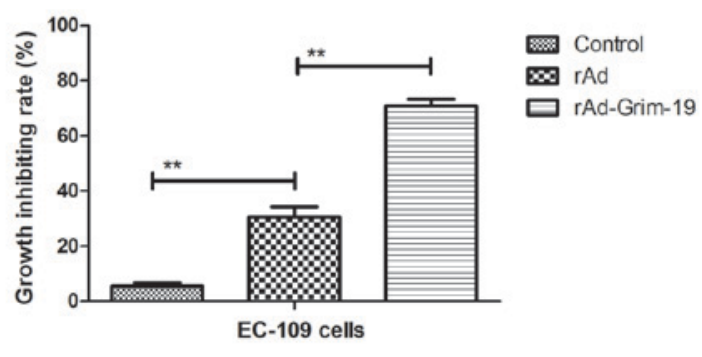

Figure 2. Characteristics of rAd-Grim-19 and in vitro effects on tumor cells. (A) Immunofluorescence was performed to analyze the expression of Grim-19 in EC-109 cells by fluorescent microscopy (magnification, x40). (B) Concentration levels of Grim-19 in supernatants of EC-109 cells infected with rAd-Grim-19 were detected by ELISA. (C) Kinetics growth curve of rAd-Grim-19 was determined through pfu/ml analysis. (D) Inhibitory effects of rAd-Grim-19 on EC-109 cell growth were determined by MTT assays. Data are presented as the mean \pm standard error of the mean of triplicate experiments.* $\mathrm{P}<0.01$, as indicated. rAd, recombinant adenovirus; Grim-19, gene associated with retinoid-interferon-induced mortality-19; pfu, plaque-forming units.

A

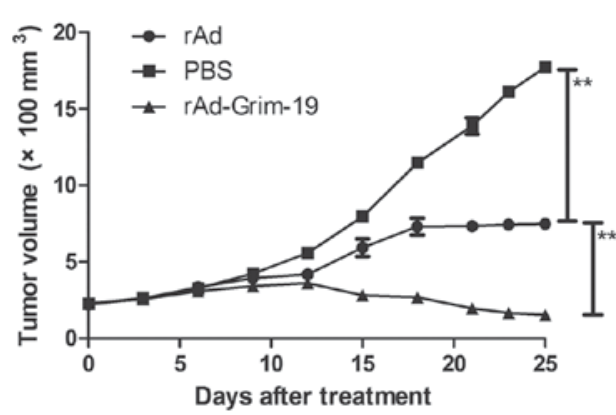

C

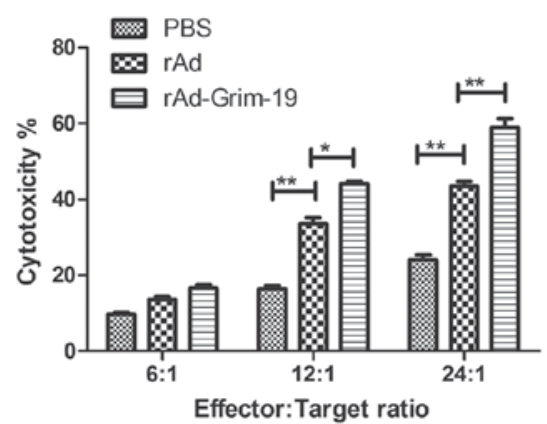

B

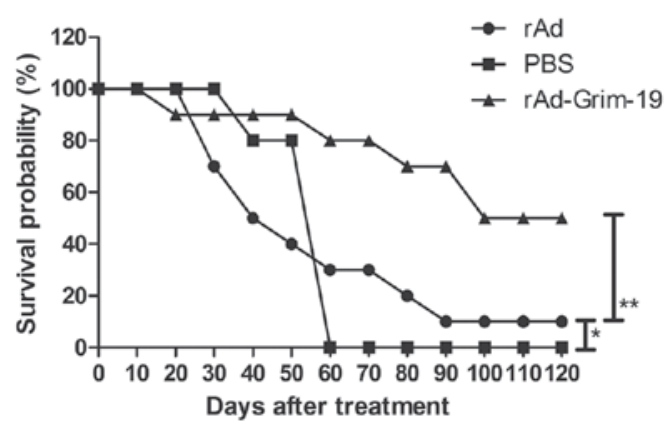

D

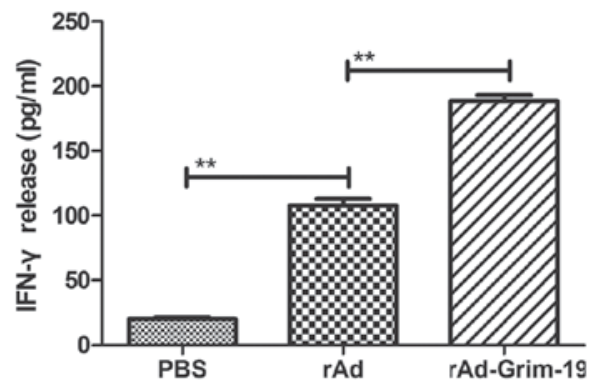

Figure 3. Therapeutic effects of rAd-Grim-19 on EC-109-bearing BALB/c nude mice. (A) Tumor growth was inhibited in EC-109-bearing BALB/c nude mice following treatment with rAd-Grim-19. (B) Survival of xenograph mice was prolonged in rAd-Grim-19-treated miceduringa 120-day observation period. (C) Cytotoxic T lymphocyte responses were enhanced by rAd-Grim-19 treatment in xenograph mice. (D) Tumor-specific IFN- $\gamma$ release was increased in esophageal neoplasm mice treated with rAd-Grim-19. Similar results were obtained in three independent experiments. ${ }^{*} \mathrm{P}<0.05$ and ${ }^{* *} \mathrm{P}<0.01$, as indicated. $\mathrm{rAd}$, recombinant adenovirus; Grim-19, gene associated with retinoid-interferon-induced mortality-19; IFN, interferon.

rAd and PBS groups. In addition, Grim-19 expression levels in tumors on day 25 after treatment were also determined. The results demonstrated that rAd-Grim-19 promoted Grim-19 expression following infection with rAd-Grim-19 in tumors 
A
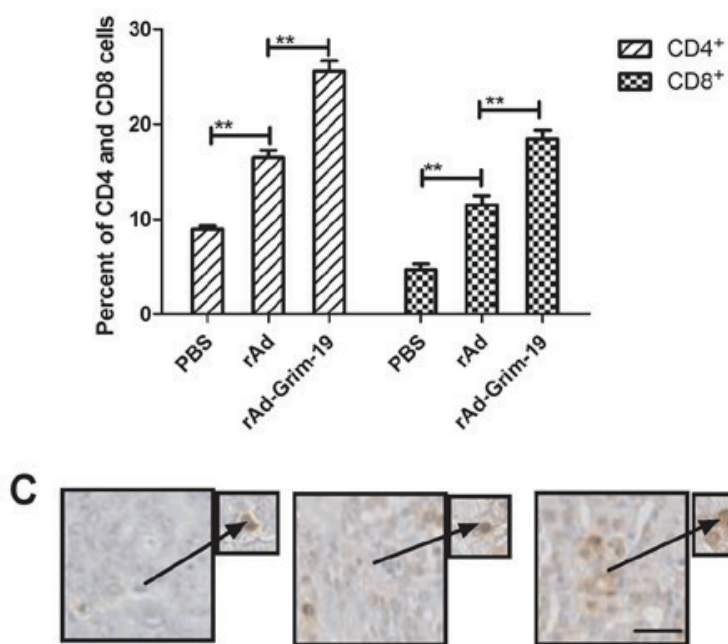

PBS
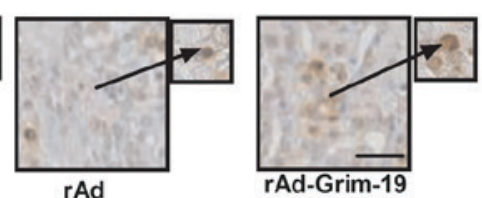

B

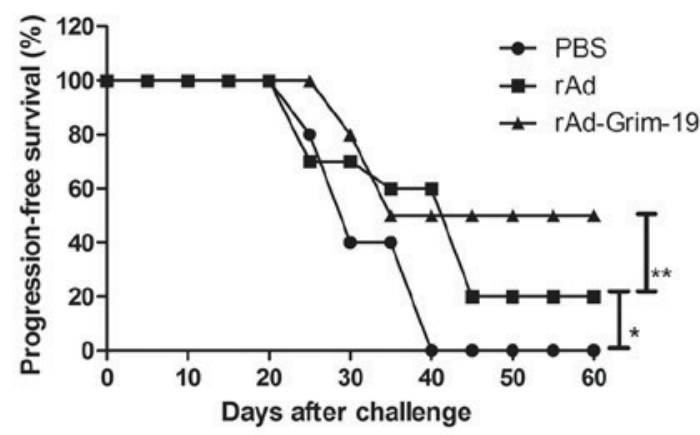

D

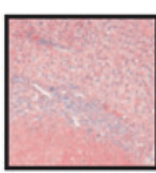

PBS

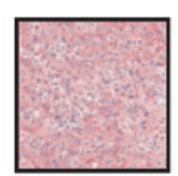

rAd



Figure 4. rAd-Grim-19 enhanced immune cell accumulation and Grim-19 expression in vivo. (A) The percentage of CD4 ${ }^{+}$and CD8 ${ }^{+}$cells in tumors from esophageal neoplasm mice was analyzed by fluorescence-activated cell sorting. (B) Immune memory was stimulated by rAd-Grim-19 in tumor challenge experiments. (C) Apoptotic bodies were increased in mouse tumors following rAd-Grim-19 treatment (magnification, x40; scale bar, $5 \mu$ m). (D) Grim-19 expression was increased in rAd-Grim-19-tumors on day 25 after treatment (magnification, $\mathrm{x} 40$; scale bar, $5 \mu \mathrm{m}$ ). Similar results were obtained in three independent experiments. Blue color indicated Grim-19 expression. $\mathrm{P}<0.05$ and ${ }^{* *} \mathrm{P}<0.01$, as indicated. rAd, recombinant adenovirus; Grim-19, gene associated with retinoid-interferon-induced mortality-19.

compared with rAd and PBS-treated tumors (Fig. 4D). In conclusion, these results indicate that rAd-Grim-19 led to beneficial outcomes for mice with esophageal neoplasms potentially through increased immune accumulation and immune memory against homologous tumor cells, which may contribute to the formation of apoptotic bodies, improve long-term survival in mice and reduce the risk of recurrence.

\section{Discussion}

Patients with esophageal neoplasms frequently receive surgery, chemotherapy, radiotherapy, immunotherapy and comprehensive therapythatin majority of cases results in deaths and represents a global health burden (30). Patients with esophageal neoplasms are frequently diagnosed at an advancedstage, and combined treatment with 5-fluorouracil and cisplatin with concurrent irradiationisa standard treatment regimen $(31,32)$. In addition, statistics have indicated that ESCC and EA account for 95 and $5 \%$ of esophageal cancer diagnoses, respectively, with ESCC accounting for the highest number of cases, and being associated with poor survival outcome and a high mortality rate (33). Given the higher morbidity and mortality, the identification and development of novel strategies for the treatment of esophageal neoplasms are required to improve the treatment and eradication of these tumors. In the present study, a mouse model of esophageal neoplasms was established to analyze the tumor growth and long-term survival following treatments.

Grim-19 is a protein with a molecular weight of $\sim 16 \mathrm{kDa}$ that was isolated as a novel gene product by using a genetic technique and was reported to enhance tumor cell apoptosis and death induced by IFN/retinoic acid (RA) (34). It is established that the Src-family of tyrosine kinases are important regulators of the cell growth, migration and invasion of various tumor cell types. Inactivation of Src by mutation caused cellular transformation through alterations in transcription and cytoskeletal properties (35). Kalakonda et al (36) reported that the tumor suppressive protein Grim-19 inhibited Src-induced oncogenic transformation. In addition, previous studies have also investigated the mechanisms of anticancer effects of IFN- $\beta$ and RA in human tumor cells. Grim-19 upregulation exhibited antitumor effects that occurred via IFN- $\beta$ and RA in human tumor cells $(15,34)$. In the current study, the results demonstrated that Grim-19 expression was reduced in EC-109 tumor cells compared with Het-1 A normal esophageal epithelial cells, and overexpression of Grim-19 inhibited EC-109 growth and induced tumor cell apoptosis.

Previous studies have demonstrated that recombinant adenoviruses based on the Adeno-X expression system resulted in a gene and oncolytic therapy vehicle for certain types of human carcinoma $(23,37)$. The recombinant adenovirusvehicle is the most widely used gene therapy vector to deliver functional protein in preclinical and clinical applications for the treatment of various human diseases, including cancer (38). In the present study, the oncolytic protein Grim-19 delivered by recombinant adenovirus was constructed and the in vitro and in vivo rAd-GRIM-19 inhibitory effects on esophageal cancer tumor growth were investigated. The results indicated that rAd-GRIM-19 significantly suppressed tumor growth in EC-109-bearing mice. However, there are few reports concerning immunotherapy delivered by a recombinant adenovirus.

A previous study reported that dysregulation of Grim-19 expression in human renal cell carcinomas and proapoptotic inactivity were mediated by signal transducer and activator of transcription 3 and JAK signaling pathways, indicating that Grim-19 may be a potential tumor suppressor that may be useful for cancer therapy development (39). In addition, Grim-19 overexpression in various human tumor cells led to reduced cell growth and apoptosis induction via IFN- $\beta$ and RA-activated 
regulator of cell death (40). The results of the current study indicated that esophageal tumor cells exhibited reduced Grim-19 mRNA and protein expression compared with normal esophageal epithelial cells. Grim-19 has been associated with reactive oxygen species induced by an IFN/RA pathway and has a conserved evolutionary history in eukaryotic cells $(41,42)$.

In addition, the present study also demonstrated that CTL responses and IFN- $\gamma$ release were significantly enhanced following rAd-GRIM-19 treatment compared with rAd and PBS treatments. The enhanced cytotoxic sensitivity of tumor cells induced by rAd-Grim-19 treatment was also associated with improvements in the long-term survival and immune memory of mice. Furthermore, tumor cells from mice treated with rAd-GRIM-19 exhibited higher levels of CD4+ and CD8+ cella ccumulation, which enhanced immunotherapy in esophageal neoplasm mice. Importantly, the volume of tumors was significantly reduced in rAd-GRIM-19-treated mice compared with rAd and PBS-treated tumors, indicating that stronger immunotherapy may be stimulated by rAd-GRIM-19 in vivo. Therefore, therapeutic effects against esophageal neoplasm cells in xenograph mice were achieved through treatment with rAd-GRIM-19. Based on the results of the present study, rAd-GRIM-19 may have potential as an anticancer strategy for future clinical trials for esophageal neoplasm and potentially other types of cancer.

\section{Acknowledgements}

Not applicable.

\section{Funding}

No funding was received.

\section{Availability of data and materials}

The analyzed data sets generated during the study are available from the corresponding author on reasonable request.

\section{Authors' contributions}

JS, WS and SZ analyzed, and interpreted the patient data regarding the esophageal neoplasm and SZ was the major contributor in writing the manuscript. WW and YZ performed the animal experiments in the present study.

\section{Ethics approval and consent to participate}

Both human and animal experiments were approved by Ethics Committee of the First Affiliated Hospital of Soochow University. Written informed consent was signed by all participants.

\section{Consent for publication}

Not applicable.

\section{Competing interests}

The authors declare that they have no competing interests.

\section{References}

1. Straatman J, Joosten PJ, Terwee CB, Cuesta MA, Jansma EP and van der Peet DL: Systematic review of patient-reported outcome measures in the surgical treatment of patients with esophageal cancer. Dis Esophagus 29: 760-772, 2016.

2. Fahey PP, Mallitt KA, Astell-Burt T, Stone G and Whiteman DC: Impact of pre-diagnosis behavior on risk of death from esophageal cancer: A systematic review and meta-analysis. Cancer Causes Control 26: 1365-1373, 2015.

3. Yodying H,Matsuda A, Miyashita M, Matsumoto S, Sakurazawa N, Yamada M and Uchida E: Prognostic significance of neutrophil-to-lymphocyte ratio and platelet-to-lymphocyte ratio in oncologic outcomes of esophageal cancer: A systematic review and meta-analysis. Ann Surg Oncol 23: 646-654, 2016.

4. Parry K, Ruurda JP, van der Sluis PC and van Hillegersberg R: Current status of laparoscopic transhiatal esophagectomy for esophageal cancer patients: A systematic review of the literature. Dis Esophagus 30: 1-7, 2017.

5. Gong J, Huang Z and Huo JR: Involvement of F-box proteins in esophageal cancer (Review). Int J Oncol 48: 886-894, 2016.

6. Tian X, Zhou JG, Zeng Z, Shuai T, Yi LJ, Ma L, Wang Y, Cao H and Song GM: Cetuximab in patients with esophageal cancer: A systematic review and meta-analysis of randomized controlled trials. Med Oncol 32: 127, 2015.

7. Du D, Song T, Liang X, Fang M and Wu S: Concurrent chemoradiotherapy with elective lymph node irradiation for esophageal cancer: A systemic review and pooled analysis of the literature. Dis Esophagus 30: 1-9, 2017.

8. Goense L, van Rossum PS, Reitsma JB, Lam MG, Meijer GJ, van Vulpen M, Ruurda JP and van Hillegersberg R: Diagnostic performance of ${ }^{18} \mathrm{~F}$-FDG PET and PET/CT for the detection of recurrent esophageal cancer after treatment with curative intent: A systematic review and meta-analysis. J Nucl Med 56: 995-1002, 2015.

9. Chung CS, Lo WC, Lee YC, Wu MS, Wang HP and Liao LJ: Image-enhanced endoscopy for detection of second primary neoplasm in patients with esophageal and head and neck cancer: A systematic review and meta-analysis. Head Neck 38 (Suppl 1): E2343-E2349, 2016

10. Koo J, Wang X, Owonikoko TK, Ramalingam SS, Khuri FR and Sun SY: GSK3 is required for rapalogs to induce degradation of some oncogenic proteins and to suppress cancer cell growth. Oncotarget 6: 8974-8987, 2015.

11. Bahlawane C, Eulenfeld R, Wiesinger MY, Wang J, Muller A, Girod A, Nazarov PV, Felsch K, Vallar L, Sauter T, et al: Constitutive activation of oncogenic PDGFR $\alpha$-mutant proteins occurring in GIST patients induces receptor mislocalisation and alters PDGFR $\alpha$ signalling characteristics. Cell Commun Signal 13: 21, 2015.

12. Hakimi R: Treatment of a questionable prostate carcinoma recurrence with oncolytic viruses, dendritic cells and heat shock proteins in established naturopathy practice. Versicherungsmedizin 64: 87-88, 2012 (In German).

13. Kalakonda S, Nallar SC, Jaber S, Keay SK, Rorke E, Munivenkatappa R, Lindner DJ, Fiskum GM and Kalvakolanu DV: Monoallelic loss of tumor suppressor GRIM-19 promotes tumorigenesis in mice. Proc Natl Acad Sci USA 110: E4213-E4222, 2013.

14. Wen LJ, Gao LF, Jin CS, Zhang HJ, Ji K, Yang JP, Zhao XJ, Wen MJ and Guan GF: Small interfering RNA survivin and GRIM-19 co-expression salmonella plasmid inhibited the growth of laryngeal cancer cells in vitro and in vivo. Int J Clin Exp Pathol 6: 2071-2081, 2013.

15. Li M, Li Z, Liang C, Han C, Huang W and Sun F: Upregulation of GRIM-19 suppresses the growth of oral squamous cell carcinoma in vitro and in vivo. Oncol Rep 32: 2183-2190, 2014.

16. Kalakonda S, Nallar SC, Lindner DJ, Sun P, Lorenz RR, Lamarre E, Reddy SP and Kalvakolanu DV: GRIM-19 mutations fail to inhibit v-Src-induced oncogenesis. Oncogene 33: 3195-3204, 2014.

17. Cheng Y, Zhang HY, Zhou Y, Tao F and Yu YH: Decreased expression of GRIM-19 and its association with high-risk HPV infection in cervical squamous intraepithelial neoplasias and cancer. Clin Invest Med 37: E77-E84, 2014.

18. Zou W, Luo C, Zhang Z, Liu J, Gu J, Pei Z, Qian C and Liu X: A novel oncolytic adenovirus targeting to telomerase activity in tumor cells with potent. Oncogene 23: 457-464, 2004. 
19. Li G, Jiang P, Li Y, Wang X, Huang J, Du Y and Zeshan B Effective suppression of replication of porcine reproductive and respiratory syndrome virus by adenovirus-mediated small interfering RNAs targeting ORF1b, 5 and 7 genes. J Virol Methods 157: 40-46, 2009.

20. Hernández-Alcoceba R, Sangro B and Prieto J: Gene therapy of liver cancer. Ann Hepatol 6: 5-14, 2007.

21. Woodger T: Restrainers in laboratory animal research. Lab Anim (NY) 45: 310-311, 2016.

22. Tomioka R: Expression of EGFP by adenovirus-mediated gene transfer in the central nervous system. Methods Mol Biol 515: 97-106, 2009.

23. Yan F, Zheng Y and Huang L: Adenovirus-mediated combined anti-angiogenic and pro-apoptotic gene therapy enhances antitumor efficacy in hepatocellular carcinoma. Oncol Lett 5 348-354, 2013.

24. Livak KJ and Schmittgen TD: Analysis of relative gene expression data using real-time quantitative PCR and the 2(-Delta Delta C(T)) method. Methods 25: 402-408, 2001

25. Chan YS, Wong JH, Fang EF, Pan W and Ng TB: Isolation of a glucosamine binding leguminous lectin with mitogenic activity towards splenocytes and anti-proliferative activity towards tumor cells. PLoS One 7: e38961, 2012.

26. Bustos-Valenzuela JC, Halcsik E, Bassi EJ, Demasi MA, Granjeiro JM and Sogayar MC: Expression, purification, bioactivity, and partial characterization of a recombinant human bone morphogenetic protein-7 produced in human 293T cells. Mol Biotechnol 46: 118-126, 2010.

27. Greaves MF and Brown G: Purification of human $\mathrm{T}$ and B lymphocytes. J Immunol 112: 420-423, 1974.

28. Zamarin D, Vigil A, Kelly K, Garcia-Sastre A and Fong Y: Genetically engineered Newcastle disease virus for malignant melanoma therapy. Gene Ther 16: 796-804, 2009.

29. Jang BI and Hwang MJ: Do esophageal squamous cell carcinoma patients have an increased risk of coexisting colorectal neoplasms? Gut Liver 10: 6-7, 2016

30. Law $\mathrm{S}$ and Wong J: Lymph node dissection in surgical treatment of esophageal neoplasms. Surg Oncol Clin N Am 16: 115-131, 2007.

31. Almhanna K, Hoffe S, Strosberg J, Dinwoodie W, Meredith K and Shridhar R: Concurrent chemoradiotherapy with protracted infusion of 5-fluorouracil (5-FU) and cisplatin for locally advanced resectable esophageal cancer. J Gastrointest Oncol 6 : $39-44,2015$

32. Cottreau J, Gruchy S, Kamionek M, Lauwers GY and Arnason T: Prevalence of oesophageal epidermoid metaplasia in 1048 consecutive patients and 58 patients with squamous neoplasms. Histopathology 68: 988-995, 2016.
33. Aksel' EM, Davydov MI and Ushakova TI: Statistics of lung, stomach and esophageal cancer: Status of oncological care, morbidity and mortality. Vestn Ross Akad Med Nauk: 61-65, 2001 (In Russian)

34. Kalakonda S, Nallar SC, Lindner DJ, Hu J, Reddy SP and Kalvakolanu DV: Tumor-suppressive activity of the cell death activator GRIM-19 on a constitutively active signal transducer and activator of transcription 3. Cancer Res 67: 6212-6220, 2007.

35. Gortat A, San-Roman MJ, Vannier C and Schmidt AA: Single point mutation in Bin/Amphiphysin/Rvs (BAR) sequence of endophilin impairs dimerization, membrane shaping, and Src homology 3 domain-mediated partnership. J Biol Chem 287: 4232-4247, 2012.

36. Kalakonda S, Nallar SC, Gong P, Lindner DJ, Goldblum SE, Reddy SP and Kalvakolanu DV: Tumor suppressive protein gene associated with retinoid-interferon-induced mortality (GRIM)-19 inhibits src-induced oncogenic transformation at multiple levels. Am J Pathol 171: 1352-1368, 2007.

37. Sinkovics JG and Horvath JC: Natural and genetically engineered viral agents for oncolysis and gene therapy of human cancers. Arch Immunol Ther Exp (Warsz) 56 (Suppl 1): 3S-59S, 2008.

38. Zhang MM, Yan LN, Li DH, Gou XH, Liu JW, Su Z, Han L and Zhao LY: Inhibition of adenovirus-mediated gene transfer of antisense matrix metalloproteinase-2 on hepatocellular carcinoma growth in vivo. Zhonghua Gan Zang Bing Za Zhi 13: 671-674, 2005 (In Chinese).

39. Alchanati I, Nallar SC, Sun P, Gao L, Hu J, Stein A, Yakirevich E, Konforty D, Alroy I, Zhao X, et al: A proteomic analysis reveals the loss of expression of the cell death regulatory gene GRIM-19 in human renal cell carcinomas. Oncogene 25: 7138-7147, 2006.

40. Chidambaram NV, Angell JE, Ling W, Hofmann ER and Kalvakolanu DV: Chromosomal localization of human GRIM-19, a novel IFN-beta and retinoic acid-activated regulator of cell death. J Interferon Cytokine Res 20: 661-665, 2000.

41. Zhang XY, Li M, Sun K, Chen XJ, Meng J, Wu L, Zhang P, Tong $X$ and Jiang WW: Decreased expression of GRIM-19 by DNA hypermethylation promotes aerobic glycolysis and cell proliferation in head and neck squamous cell carcinoma. Oncotarget 6: 101-115, 2015.

42. Chao L, Wang X, Yang Y, Cui W, Xu J, Chen H, Hao A and Deng X: Downregulation of gene expression and activity of GRIM-19 affects mouse oocyte viability, maturation, embryo development and implantation. J Assist Reprod Genet 32: 461-470, 2015. 